\title{
ir
}

\section{EL ÁRBOL DEL MEJOR FRUTO DE CALDERÓN Y LA LEYENDA DEL ÁRBOL DE LA CRUZ. CONTEXTOY ADAPTACIÓN}

\author{
Ignacio Arellano \\ GRISO. Universidad de Navarra \\ [Anuario calderoniano (ISSN: 1888-8046), 1, 2008, pp. 27-65]
}

Un tejido de leyendas sobre el árbol de la cruz

El árbol del mejor fruto reelabora un conjunto de materiales relativos a Salomón, la reina de Sabá y el madero de la cruz, transmitido por múltiples vías en muchas versiones de abundante contaminación ${ }^{1}$.

Según el argumento del auto Salomón recibe el encargo de Dios de hacer un templo (libro 3 de los Reyes) y envía a sus mensajeros a recoger materiales. En el Líbano talan un árbol extraordinario, que llevan para el templo. La reina de Sabá acude a visitar a Salomón, cuya fama y sabiduría son inigualables. En Jerusalén la reina propone una

${ }^{1}$ Una versión más amplia de estos comentarios forma parte del estudio introductorio a mi edición crítica de El árbol del mejor fruto, en prensa, y por la que cito aquí el texto del auto. En ese estudio trato otros detalles en los que ahora no me detengo, como la datación o circunstancias de la obra. Este trabajo se enmarca en una investigación que cuenta con ayuda del Ministerio de Educación (HUM200403648/FILO) y del Gobierno de Navarra, Departamento de Educación (Proyectos de Investigación de interés para Navarra, convocatoria 2005). 
serie de enigmas a Salomón, en cuyas soluciones demuestra el rey su ciencia. Para pasar el arroyo Cedrón colocan el madero del Líbano a modo de puente: la reina al verlo entra en éxtasis y explica el sentido cristológico y salvífico de ese "árbol del mejor fruto", cuya leyenda resume, desde las semillas del árbol de la ciencia del bien y del mal hasta la colocación del madero en la piscina probática y luego la fabricación de la cruz con él.

La protagonista, reina de Sabá, aparece mencionada en diversos lugares de la Biblia: 2 Reyes 10, 1; salmo 71, 10; Isaías 60, 6... El nombre de la reina de Sabá que visitó a Salomón no consta en los escritos bíblicos, aunque Calderón en varias obras siempre se refiere a ella como Nicaula. Cornelius a Lapide en sus comentarios al tercer libro de los Reyes (cap. X, 1) la llama Nicaula Maqueda siguiendo a distintos autores, especialmente a Flavio Josefo ${ }^{2}$, quien dedica una sección de su libro VIII de Antigüedades judías a la visita de la reina de Sabá a Salomón. Nicaula Maqueda es el nombre que Calderón le atribuye en la versión de comedia La sibila del oriente (pp. 714-715) ${ }^{3}$.

Edward Glaser ${ }^{4}$, a propósito de esta comedia de La sibila del oriente (no toma en consideración el auto) repasa fuentes bíblicas y apócrifas para algunos motivos que resultan comunes con el auto, señalando lugares tomados al libro de los Reyes, Cantar de los cantares, evangelio de San Lucas y Virgilio. En el ámbito español hay bastantes tratamientos de la tradición de las sibilas (Pero Mexía, Juan de Orozco y Covarrubias, Baltasar Porreño, Alonso de Horozco.... $)^{5}$. Luis de Urreta en su Historia eclesiástica, texto aportado por Glaser, explica con cierta fantasía las revelaciones que experimenta esta "sibila» que fue la reina de Sabá «a la cual en toda la Etiopia la llaman sibila»:

De esta ilustre reina dicen muchos doctores que le fue revelado el misterio de la Santísima Cruz, donde había de morir Cristo, divino Mesías. [...] la reina Sabá, volviéndose a su tierra muy contenta y alegre, llegó a un arroyo y gollizno, en el cual había un madero y palanca que servía de

${ }^{2}$ Manejo Antigüedades judías en la ed. de J.Vara Maldonado, pp. 459-462.

${ }^{3}$ Cito La sibila del oriente por la edición de Valbuena Briones en Obras completas de Calderón. Dramas, 1987.

4 Glaser, 1960.

${ }^{5}$ Ver Glaser, 1960, pp. 386-387, también para alguna bibliografia útil sobre la leyenda de la reina de Sabá. Las citas de Urreta las aduce en pp. 388-390. 
puente, y le fue entonces revelado que en aquel santo madero había de ser crucificado Cristo...

Describe Urreta algunas pinturas de Etiopia, en una de las cuales

la reina Sabá, extendido el brazo, alargando el dedo, señala un árbol de los de la huerta, y el rey Salomón mirando el árbol con un ademán que descubre una grande admiración y de la boca le sale un letrero que en la lengua etiopia dice Iascuz bene mihi sarapha, que es decir «debajo de este árbol fue hecho el gran mal y debajo dél resucitará el gran bien»...

Glaser no olvida citar a Juan de Pineda, cuya obra Salomon praevius id est de rebus Salomonis, me parece relevante en la consideración del auto calderoniano. Pineda trata extensamente de la reina de Sabá y del árbol de la cruz, recogiendo pasajes del anónimo Fioreto novello del Testamento vecchio e novo, texto del que hablaré más adelante. En lo que a la sibila respecta, Pineda ${ }^{6}$ comenta la variedad de los nombres que se le atribuyen en las fuentes antiguas (Nicaula, Maqueda, Nitocris, Candaces...), la situación y condiciones de su reino, sus creencias y religión, algunas cuestiones de filología onomástica, cronología de su viaje a Jerusalén, y describe la visita de la reina a la corte de Salomón, su conversión, visiones y oráculos sobre el árbol de la cruz. Una parte importante dedica a la curiosidad intelectual de la reina y a los enigmas que propone al rey.

Algunos elementos que usa Calderón provienen de la Eneida. La escena de los vv. 388 y ss., con el trance de la sibila, son reescritura del modelo virgiliano (libro III), sobre la sibila de Cumas. Compárese el texto de Virgilio con el de Calderón:

Una vez allí llegarás a la ciudad de Cumas y a los lagos divinos y al Averno resonante de bosques, verás a la vidente frenética que al fondo de una roca canta el destino y confía a las hojas señales y nombres. Cuantas respuestas escribe la virgen en las hojas las pone en orden y las deja encerradas en la cueva; allí permanecen sin moverse en su lugar y no se apartan de su sitio. Ahora, cuando al girar los goznes suave ráfaga de viento las empuja y agita las tiernas hojas, revolotean por el cavo peñasco y

${ }^{6}$ Me refiero a la edición de 1609, pp. 399-418. 
ya de recogerlas no se cuida ni de ponerlas en su lugar o juntar las respuestas: se alejan sin contestación y odian la sede de la Sibila. (Virgilio)

\section{Sale SABÁ y va arrojando hojas de árboles al viento}

SABÁ

Espíritu divino

que sin duda en aquesa azul esfera

causa de causas es causa primera:

pues a ti sola invoco

cuando el principio del principio toco,

ya que escribir me dejan mis congojas

en hojas de los árboles, que hojas

son del papel del viento,

lo que me dictas, cóbrame en mi aliento

para decir: «Sabed, sabed, mortales, que sé de la salud de vuestros males.

Esas líneas que lleva divididas

el aire, en verde lámina esculpidas, misterios comprehenden

que solo las estrellas los entienden... (vv. 389 y ss.)

El núcleo argumental del auto, conectado con los episodios de la sibila y Salomón, es la leyenda del leño de la cruz. Calderón maneja un mosaico de motivos que constan en innumerables textos desde el Evangelio de Nicodemo (antes del siglo V) que parece ser el primero que recoge parte de la leyenda.

La leyenda del árbol de la cruz se halla relacionada con otro paralelo (antitético) previo que se establece entre Adán y Cristo. Como escribe Mussafia ${ }^{7}$ :

Sin da' primi tempi della Chiesa la tradizione si studiò di stabilire continuo parallelismo fra il peccato e la redenzione. Cristo è nuovo Adamo, Maria nuova Eva o un' Eva rivoltata (Ave); la bocca peccó, dalla bocca sorga il riscatto; arbor ligni pestiferum decepti pabulum praebuit, lignum crucis vitam immortali compage restituit; Adamo è sepolto nel Golgota e su di esso gronda il sangue di Cristo, e così via. Poi il parallelismo, quando potè, mutossi in identità; non un albero danna l'umanità ed un altro la libera,

${ }^{7}$ Mussafia, 1869, p. 165. 
ma su quello stesso albero che fu strumento del peccato deve operarsi la redenzione.

El paralelismo entre pecado y redención exige que el pecador Adán reciba la sangre redentora en el mismo lugar de la caída, lo cual significa que el árbol del Paraíso estaba en el mismo lugar que el de la cruz, o bien que la calavera de Adán (que figura en muchas pinturas de la Crucifixión al pie de la cruz) ha tenido que ser transportada al Gólgota. Esta segunda posibilidad es la más frecuente. Según distintas versiones el cráneo de Adán habría sido llevado a Judea por Sem, hijo de Noé, en cuya arca se transportaron los huesos del padre de la humanidad durante el diluvio. Juan de Solórzano Pereira ${ }^{8}$, por ejemplo, escribe:

Agustín Torniello cree que en estas palabras se esconde otro misterio, según las tradiciones sirias, siguiendo a Andrés Maes, a saber, que Noé llevó religiosamente consigo al arca los huesos de nuestro primer padre Adán y después del diluvio [...] los repartió entre sus tres hijos al tiempo que les repartía también el mundo: a Sem, a quien dio preferencia sobre los demás, le concedió la calavera y juntamente con ella esa región que ahora llamamos Judea...

Calderón recoge el motivo en Primero y segundo Isaac (vv. 35 y ss.), precisando el lugar exacto de la sepultura de la calavera de Adán ${ }^{9}$ :

LUCERO ... éste es Calvario, a quien en tradiciones comunes

${ }^{8}$ De indiarum iure, liber I, p. 323.

${ }^{9}$ En algunas versiones es la osamenta completa la que Sem deposita en el Gólgota, que es el centro de la tierra, guiado por un ángel. Cuando Sem pone el cuerpo de Adán en ese lugar «los cuatro puntos cardinales uno a uno se separaron y la tierra se abrió en cruz. Inmediatamente después de que Sem y Melquisedec pusieran allí el cuerpo de Adán los cuatro puntos cardinales corrieron, se pararon unos frente a otros y abrazaron su cuerpo. Inmediatamente se cerró la puerta de aquel lugar.Y aquel lugar fue llamado Calavera, porque en él se puso la cabeza de todos los hombres [...] Aquel lugar es el centro de la Tierra, la sepultura de Adán, el altar de Melquisedec, el Gólgota, el Calvario y la Calavera. Allí David vio al ángel que portaba la espada de fuego. Allí Abraham elevó a Isaac sobre el altar y vio a Cristo, vio la cruz de su salvación y de la salvación de nuestro padre Adán» (La cueva de los tesoros, pp. 130131). 


\begin{abstract}
dio este blasón del cadáver de Adán la parte que ilustre cupo, como a mayorazgo, a Sem; de donde se arguye (por ser de su calavera la tumba que le sepulte), el ser Calvario su nombre.
\end{abstract}

El paralelo entre Adán y Cristo incluye muchos aspectos: según una relación de La cueva de los tesoros ${ }^{10}$, el pecado se cometió en la hora sexta, y a la misma hora fue la redención; en viernes se pecó y en viernes se perdonó el pecado, etc. Calderón en La inmunidad del sagrado desarrolla extensamente este paralelismo (vv. 1240 y ss.):

Culpa Segundo Adán, ¿dónde o cuándo

le hay?

MERCADER

Ve acordando el primero, irás el segundo hallando.

Culpa El primero Adán, del sumo poder de Dios, fue criado a su hechura y semejanza en el damasceno campo.

Mercader De ese mismo poder fue, si no criado, engendrado a imagen suya el segundo Adán en el real palacio de más superior esfera.

Culpa El primero, trasladado del hermoso paraíso, fue al verde florido espacio.

Mercader También el segundo, pues fue el primero feliz paso que dio al bello paraíso

${ }^{10}$ La cueva de los tesoros, pp. 185-186. Se trata de un conjunto de tradiciones sobre la historia de la Salvación, que recoge relatos muy antiguos y que se transmite en versiones árabes, etiópicas, coptas, siríacas, etc. Manejo la traducción de González Casado. 
de un virgen fecundo claustro.

Culpa

La feria sexta o el día

sexto, a quien después llamaron

véneris, fue del primero

Adán el oriente claro.

Mercader El día viernes, del segundo, no fue oriente sino ocaso; que en él, lo que erró naciendo uno, otro enmendó expirando.

Culpa El primero, por hacerse divino, quebró un mandato.

Mercader El segundo, por cumplir un decreto, se hizo humano. $[\ldots]$

Culpa Entre ella y la sexta, éste extendió al árbol la mano.

Mercader $\quad Y$ estotro, entre tercia y sexta, también extendió los brazos sobre el ara de la cruz.

El paralelo más importante para el auto El árbol del mejor fruto es, naturalmente, el de los dos árboles, el del pecado y el de la redención.

Del siglo I datan algunas versiones griegas y latinas de la vida de Adán $^{11}$ que incluyen distintos episodios de la enfermedad de Adán y viaje de su hijo Set al Paraíso en busca del óleo de la salud. El Evangelio de Nicodemo, hacia el siglo $\mathrm{v}$, es un nuevo hito de la historia que durante los siglos XII y XIII se extenderá con múltiples ramificaciones que estudian Mussafia y Combes ${ }^{12}$.

Una síntesis que puede orientar para la comprensión del auto calderoniano sería la siguiente.

Al llegar Set al Paraíso en busca de medicina para su padre agonizante, ve el árbol de la ciencia, seco y rodeado de la serpiente; después lo ve lozano, con un niño de hermosura incomparable en su

${ }^{11}$ Ver Apócrifos del Antiguo Testamento, tomo II.

12 Mussafia, 1869 y Combes, 1901. Sigo en los párrafos siguientes principalmente los datos proporcionados por estos trabajos. 
copa, y sin la serpiente tentadora. El ángel guardián (San Miguel según muchas versiones) explica a Set el misterio de la redención y le da tres simientes del árbol viejo, de las cuales saldrá el árbol nuevo que producirá la madera para la cruz. Las simientes se siembran en la boca de Adán y de ellas brota un árbol que ya ha crecido en tiempo de Salomón. El rey quiere usarlo en el templo, pero no puede adaptarse a ninguna medida. Cuando la reina de Sabá visita Jerusalén cae en trance al ver el árbol (en el maderamen de una sala de palacio, o colocado como puente para pasar un arroyo: versión esta última que adopta Calderón) y profetiza que ese árbol servirá para la elevación de un enviado celestial, y/o causa del fin del reino judío. Salomón lo entierra en un lugar donde se construirá más tarde la piscina probática, y en el tiempo de la Pasión emerge misteriosamente, siendo usado para fabricar la cruz.

Las versiones más difundidas pertenecen a dos familias principales: aquellas en la que Adán o Set sacan del Paraíso un esqueje del árbol, y aquellas en las que Set se lleva tres simientes. Sea cual fuere el origen de la planta (esqueje o semillas) se asocia con Salomón y las visiones de la reina de Sabá.

En el extenso relato latino Poenitentia Adae (anterior al siglo XIII) Eva acompaña a Set al Paraíso; en la variante de un manuscrito de Viena ${ }^{13}$ San Miguel da a ambos un ramo con tres hojas del árbol de la ciencia del bien y del mal, ordenando que se plante sobre la tumba de Adán. Nace un árbol que en tiempo de Salomón se coloca en el templo; la reina de Sabá al verlo vaticina que de él procederá la destrucción del reino de los judíos, y Salomón lo deposita en la probática piscina, donde sucederán las curaciones de los enfermos en la época de Jesucristo "qui in ipso ligno suspensus est in eo qui dicitur Calvarie locus et in ipso stipite arboris posito ut sanguis ipsius redemptoris in caput primi plasmatis descenderit».

Una de las versiones más claras, completas y conocidas es la de Jacobo de la Voragine (siglo XIII) en la Leyenda dorada ${ }^{14}$, donde aparece un detalle importante para el tratamiento calderoniano: el de las especies de árbol o clases de madera que componen el tronco mara-

13 Citado por Mussafia, 1869, p. 169.

14 Leyenda dorada, I, pp. 287-288. 
villoso nacido del tallo original, del cual brotan tres árboles o un árbol tríplice:

el arcángel entregó a Seth un ramito o tallo y que le mandó que lo plantara en el monte Líbano; y en una historia apócrifa de los griegos se dice que el tallo que San Miguel dio a Seth procedía del árbol que sirvió de ocasión al pecado de Adán, y que al entregárselo a Seth, el ángel le advirtió: "Cuando este ramito se convierta en árbol y fructifique, tu padre sanará». La citada historia añade que Seth, al regresar a su morada y hallar a su padre muerto, lo enterró y plantó sobre su sepulcro el tallo, que este prendió, creció, y se convirtió andando el tiempo en un corpulento árbol y que tal duró hasta los días de Salomón [...] cuando Salomón vio aquel árbol tan magnífico, mandó que lo cortaran y que lo colocaran como viga en un palacio que a la sazón estaba construyendo [...] y Juan Beleth, por su parte, agrega: «Los constructores talaron el árbol, [...] pero la viga no encajaba en parte alguna [...] a fin de aprovecharla de alguna manera la colocaron sobre un regato para que sirviera de pasarela [...] cuando la reina de Saba fue a Jerusalén para conocer al rey Salomón, de quien tan elogiosamente había oído hablar, al acercarse al regato y ver el madero que servía de puente, por súbita sobrenatural revelación supo que sobre él había de morir el Salvador del mundo» [...] Salomón mandó retirar la viga y esconderla en las entrañas de la tierra [...] pasado mucho tiempo, en el lugar en que la viga fue enterrada se construyó la piscina probática [...] antes de la Pasión de Cristo la viga apareció flotando [...] y posteriormente la utilizaron para confeccionar con su madera la cruz en que clavaron al Salvador.

Otra tradición asegura que la cruz de Cristo estaba hecha con madera de cuatro árboles de diferente especie, a saber: con madera de palmera, con madera de cedro, con madera de ciprés y con madera de olivo.

Las clases de madera de la cruz (tres o cuatro) es un tema usual en los tratados de cruce y en muchas otras fuentes. En la Edad Media predominó el número de tres, porque se hacían símbolo de la Trinidad. Pueden variar las especies mencionadas. Un texto suficientemente explicativo nos ofrece el Cedro en La humildad coronada de Calderón (vv. 897 y ss.) de la serie de palma, cedro y ciprés:

Cedro

Cedro árbol eterno es, la palma triunfos advierte, el ciprés muerte después, luego eterno hay triunfo y muerte 
en cedro, palma y ciprés.

[...] luego bien este árbol es

jeroglífico oportuno

de quien en su esencia es uno

siendo en sus personas tres.

[...] así es

de todos tres sombra y luz,

árbol que en forma de cruz

es cedro, palma y ciprés.

Gofredo de Viterbo (citado por Gretser ${ }^{15}$ en su extensa obra De Santa Cruce) cuenta el viaje de un nieto de Noé (llamado Jonito o Jonico) al Paraíso, de donde trae tres plantas de abeto, palma y ciprés. Pineda en De rebus Salomonis, o más exactamente, en el fragmento que recoge del Fioreto novello ${ }^{16}$, aporta numerosos detalles del viaje de Set al Paraíso en busca del óleo curativo, la visión del árbol marchito del pecado, el regalo del ángel guardián a Set de tres simientes y la interpretación trinitaria, entre otros detalles ya apuntados.

Los libros de Pineda y de Gretser ${ }^{17}$ me parecen los más cercanos a Calderón: si el enfoque de Pineda privilegia la figura de Salomón, el de Gretser se centra más en la cruz ${ }^{18}$.

Para nuestro tema son principales los capítulos IV y V del libro I de Gretser ( $R$ Referuntur quatuor commentitiae sententiae de materia crucis Dominicae» y «Referuntur probabiles quaedam sententiae de materia crucis Dominicae») ${ }^{19}$. Después de señalar que muchas de estas noticias son fabulosas y poco verosímiles, recoge algunas de ellas (la de Viterbo, de un manuscrito de la Biblioteca Augustana, de la

15 Gretser, De Santa Cruce, manejo la ed. de Ingolstad, 1616.

${ }^{16}$ Ver el texto pertinente del Fioreto en Pineda, De rebus, pp. 417-418.

17 Ambos jesuitas se conocen y citan mutuamente en diversas ediciones de sus obras: Pineda en la edición de 1609 cita a Gretser (por la edición de Gretser, De Cruce Christi, Ingolstadt, ex typographia Adami Sartorii, 1600) y este cita a su vez a Pineda en la edición de De Santa Cruce de 1616.

18 Otra obra que pudiera haber sido conocida de Calderón es De cruce de Justo Lipsio, pero el trabajo de Lipsio es mucho más "científico» e histórico y renuncia a hacer disquisiciones sobre los escritores antiguos que hablaron de cuatro maderas (cedro, palma, ciprés, oliva) señalando que son cuestiones más curiosas que verdaderas (Lipsius, De Cruce libri tres, p. 70).

${ }^{19}$ Me refiero, como ya he indicado, a la edición de 1616. 
Historia scholastica de Carthusianus...) en donde se menciona un tal Hionto, hijo de Noé (Gretser no lo halla en ninguna fuente fiable), que sacó del Paraíso esquejes de palma, abeto y ciprés, o se cuenta que Abraham plantó tres vástagos de pino, cedro y ciprés que crecieron formando un solo árbol, del cual quiso Salomón hacer una viga para el Templo, o se resume la visión de la reina de Sabá al pasar el Cedrón por el puente hecho del árbol maravilloso, depositado luego en la probática piscina y más tarde usado para la cruz.

Algunas notas sobre el árbol de la cruz en el teatro del Siglo de Oro y en Calderón

Enrique Rull ${ }^{20}$ llega a sugerir la existencia de una trilogía calderoniana sobre el tema salomónico, quizá no debida a un diseño premeditado del poeta, pero en todo caso perceptible, formada por Los cabellos de Absalón, La sibila del oriente y El árbol del mejor fruto, la cual tendría algunos precedentes en La venganza de Tamar de Tirso y quizá (aunque nada se puede asegurar) en una pieza perdida de Lope, El templo de Salomón.

A mi juicio La venganza de Tamar y Los cabellos de Absalón no formarían un corpus tan nítido si los observamos desde el tema central de la leyenda del árbol de la cruz tan estrechamente emparentada con la sibila oriental o reina de Sabá. Mucho más clara es la relación de la comedia y el auto calderoniano que trataré luego con más detalle. Y quizá merezca la pena comentar algunas otras piezas que creo más cercanas a este complejo temático, empezando por dos autos de Valdivielso que no son tan importantes como parecería por su título en lo que respecta a la leyenda que estoy considerando.

En efecto, en cierto episodio de El árbol de la gracia ${ }^{21}$, Gracia envía al villano Cuerpo a que traiga leña del monte del Sacrificio:

Pues al camino disponte que sus cedros altos son, que se plantó en ese monte el árbol de redención. (vv. 390-393)

${ }^{20}$ Rull, 2004, p. 223.

${ }^{21}$ Ver Valdivielso, Teatro completo. 
Cuando regresa el Cuerpo trae una cruz grande a cuestas y en la descripción de su carga integra alguna referencia a la leyenda del «tronco de Salomón", pero en un conjunto de otros muchos simbolismos de la cruz, y sin darle una relevancia particular. Al final la Gracia en su apoteosis aparece sobre un árbol de siete ramos que son los siete sacramentos: aunque según la tradición los sacramentos surgen del costado de Cristo en la cruz y este dato podría hacer identificar el árbol de la Gracia con la misma cruz, realmente se presenta como «el árbol de la Gracia» (un árbol metafórico no exactamente igual a la cruz) que está injerto en siete divinos ramos (los sacramentos), y nada sustancial hay que relacione esta pieza con el tema que ahora me interesa.

Lo mismo podría decirse de El árbol de la vida, en el que Cristo mismo es el árbol de la vida, según otra imagen, habitual en los padres de la Iglesia, pero muy distinta ${ }^{22}$ de la que da el argumento a El árbol del mejor fruto.

Ese mismo título de El árbol de la vida se atribuye en su último verso a la comedia de Tirso habitualmente conocida como El árbol del mejor fruto, sobre la invención de la cruz. Aunque poco tiene que ver su argumento con La sibila del oriente o El árbol del mejor fruto (auto de Calderón), el personaje llamado Judas cuenta una variante de la leyenda, mientras se dispone a fabricar una cruz falsa para engañar a Santa Elena y Constantino 23 :

JUDAS

$$
\begin{aligned}
& \text { Unos dicen que se hizo } \\
& \text { del árbol en que pecó } \\
& \text { Adán en el paraíso, } \\
& \text { porque desterrado de él, } \\
& \text { un ramo llevó consigo } \\
& \text { de aquella planta, que fue, } \\
& \text { nuestra pena y su castigo; } \\
& \text { y plantándole lloroso } \\
& \text { en este monte divino, } \\
& \text { donde Salomón después }
\end{aligned}
$$

${ }^{22}$ Ver para este sentido de la imagen del árbol de la vida Daniélou, 1961, pp. 33-

48 y C. a Lapide, Commentaria in Genesim, cap. II.

23 Tirso de Molina, Obras dramáticas completas, III, pp. 346-347. 
hizo el templo ilustre y rico, creció emulación del cielo, y por extraño prodigio nació una fuente del tronco, de quien a formarse vino la saludable piscina, que de dolores distintos, al movimiento del ángel, sanó tantos afligidos.

[...]

... por misterio oculto, ya siendo grande, ya chico, desmintiendo arquitectores, nunca a la fábrica vino, por lo cual desesperados, juzgándole por indigno e inútil del templo santo, mandaron que por castigo en la piscina le echasen. Hundiose, pero nacido el Nazareno que adoran los cristianos enemigos, sobre las aguas salió.

ZABULÓN

JUDAS
¡Misterio jamás oído!

Y sacándole de allí, le echaron en un camino. por donde corre en cristales el Cedrón, arroyo limpio, puesto que tal vez crecientes le dan ambición de río. Sirvió en él de puente y paso, hasta que por sus delitos a muerte de cruz sentencia el pretor romano a Cristo, que por ver que era pesado, decretaron los judíos que dél se hiciese la cruz... 
Sin duda es Calderón el dramaturgo del Siglo de Oro que más presente tiene este complejo de materiales, que integra en diversa medida en varios autos y en la comedia La sibila del oriente.

En La humildad coronada (1644) dos ángeles traen una corona que, según explica el Cedro, será para la planta que merezca ser coronada monarca de las demás, planta salvadora de la corrupción del pecado:

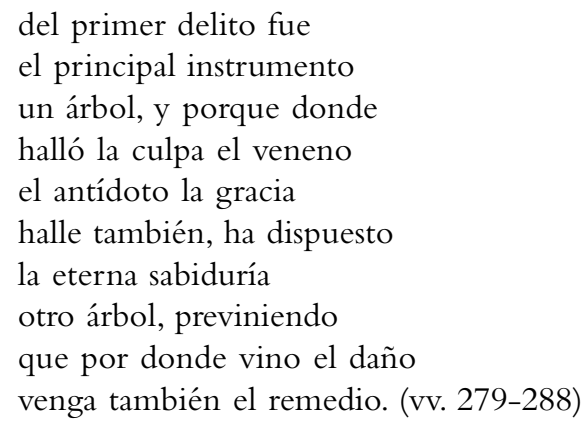

Se reconocerá en el pasaje citado evocación del paralelismo de los árboles del Paraíso y de la cruz. El Cedro sale a escena con el bastón en forma de cruz, un brazo de hojas de palma, el otro de ciprés, y en medio "otras que más imiten las del cedro", mezcla de especies que desorienta a los demás. El misterio de un árbol que es a la vez cedro, palma y ciprés se explica en vv. 898-936, subrayando su significación trinitaria. Sin embargo el árbol del mejor fruto (expresión reiterada en La humildad coronada) no será aquí la cruz, sino la espiga y la vid, dos humildes plantas que serán coronadas como expresión del más alto misterio de los misterios, el sacramento de la Eucaristía.

En La lepra de Constantino ${ }^{24}$ Calderón inserta numerosos motivos de la leyenda, estructurando la paridad de los dos árboles en forma de debate dialogado entre la Gentilidad y la Fe (vv. 1589 y ss.):

$\begin{array}{ll}\text { Gentilidad } & \text { Cuando Elena halle la cruz, } \\ \text { ¿qué misterio en sí contiene } \\ \text { un madero para que } \\ \text { en él sus auxilios pienses? }\end{array}$

${ }^{24}$ Calderón, La lepra de Constantino, ed. L. Galván y R. Arana, en prensa. 
FE

Gentilidid

FE

Gentilidid

FE

GenTILIDAD

FE

Gentilidad

FE

GENTILIDAD

FE

GENTILIDAD

FE

GENTILIDAD

FE
¿Qué más misterio que ser, si a sus prodigios atiendes, el inmediato instrumento de la redención?

Detente.

¿Es más que un leño que pudo ser horca de un delincuente?

Más es, pues del primer árbol se transplantó su simiente.

No es más, pues vemos que tronco en Gólgota nace y crece.

Más es, pues donde Adán yace es donde sus raíces prenden.

No es más, pues de ningún fruto adorna su pompa verde.

Más es, pues sin fruto sana la infición de la serpiente.

No es más, pues de cedro, palma y ciprés son sus especies.

Más es, pues, siendo tres, dice duración, victoria y muerte.

No es más, pues ruda segur para Salomón le hiere.

Más es, pues nunca le labran porque a otro fin aproveche.

No es más, pues que por inútil sirve del Cedrón al puente.

Más es, pues Sabá le adora $\mathrm{y}$ a pisarle no se atreve.

No es más, pues de allí quitado mandan que a un lago le echen.

Más es, pues de esa piscina los enfermos convalecen. 


$\begin{array}{ll}\text { GENTILIDAD } & \text { No es más, pues sobre las aguas } \\ & \text { lleno de cieno parece. } \\ \text { FE } & \begin{array}{l}\text { Más es, pues parece cuando } \\ \text { para cruz han menesterle. }\end{array}\end{array}$

En Primero y segundo Isaac coloca Calderón el sacrificio de Isaac en el Monte Calvario, donde está la calavera de Adán, dato tradicional ya estudiado, que sirve para situar la acción sacrificial en el ámbito de la tipología de Adán, expresando la conexión del sacrificio de Isaac con la caída del primer Adán, siendo Isaac figura de Cristo (segundo Adán y segundo Isaac). Este es el principal paralelismo basado en motivos de la leyenda, que no se explota en la antítesis de los árboles.

Más importante es el tratamiento de Primer refugio del hombre y probática piscina. El Demonio se halla desesperado ante un misterio que no alcanza a resolver, el de las milagrosas aguas de la probática piscina. En sus reflexiones ofuscadas el demonio menciona como elementos enigmáticos la historia de la viga del templo de Salomón, que acabó en la piscina y también la cercanía de la casa de los padres de la Virgen (donde nace María) al lugar donde estaba la piscina. En ese mismo lugar desembocaba la sangre de las reses inmoladas en sacrificio (imagen del sacrificio de Cristo), de manera que todo junto pone pavor al Demonio, que ve sanar a los enfermos (pecadores) con el baño.

El parlamento inicial del Demonio (vv. 57 y ss.) recopila todos estos motivos $^{25}$ :

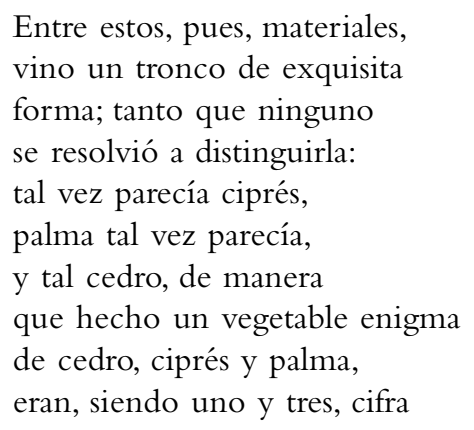

25 Calderón, Primer refugio del hombre y probática piscina, ed. R. Zafra, en prensa. 


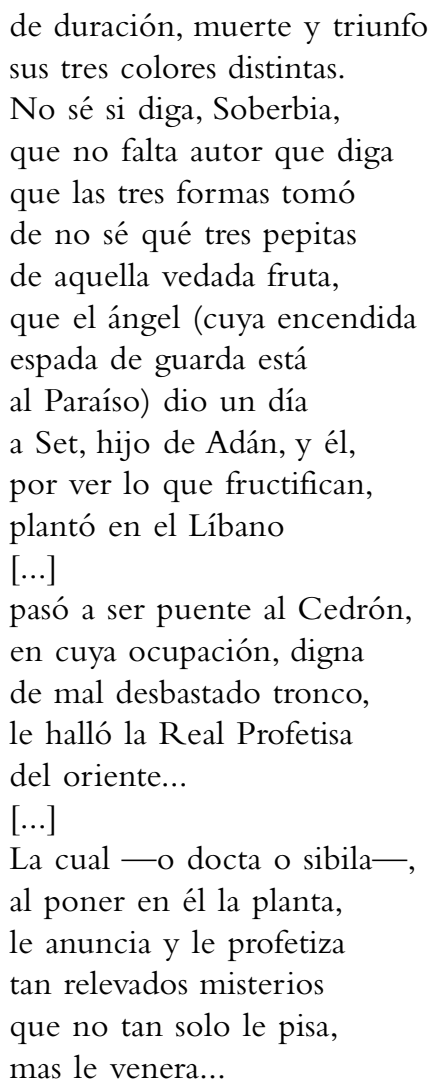

Otro auto en el que aparece una alusión menor es La redención de cautivos (p. 1324) ${ }^{26}$, inserta en un juego metafórico alusivo: el Furor se presenta alegóricamente como pirata, «revalidando el principio / de ser mar la vida». Persigue en su barco tenebroso a la nave en la que el Género Humano espera salvarse: el árbol (mástil) del Furor hace la competencia a otro árbol que se le opone. Puede verse en esta contraposición el recuerdo de la antítesis del de la ciencia del bien y del mal y el de la cruz. Que Calderón tiene en su pensamiento la leyenda se confirma más adelante (pp.1336-1337) en la escena en que Furor pelea con Isaac, usando como arma un madero sin ramas ni hojas, un

26 Calderón, La redención de cautivos, en Obras completas, III, Autos. 
«esqueleto del monte», motivo que recuerda el estado en el que Set ve al árbol del pecado en el Paraíso.

El jardín de Falerina incluye asimismo algunas referencias, poco desarrolladas en este caso, del motivo de los dos árboles. La Gracia, el Hombre y los Sentidos descansan en cierto momento a la sombra de un árbol, que antes había sido el de la sierpe tentadora, pero que ahora está transmutado en otro árbol extraordinario que

su corteza
en lo vegetable escribe
de sus arrugadas quiebras
algún gran misterio, pues
de tres especies compuestas,
de una parte es cedro y de otra
ciprés, de otra palma: señas
que me dan que discurrir
que algún enigma contenga. (vv. 455-463)

Nótese que esas mal formadas letras que se pueden leer en las arrugas misteriosas del árbol hablan en tres lenguas, griega, latina y hebrea («Y no para aquí si adviertes / que esas mal formadas letras / también en tres lenguas hablan, / griega, latina y hebrea», vv. 470-473), lo que confirma la identificación del mismo con la cruz, según escribe Juan $(19,19-20)$ : «Pilato mandó escribir el título y lo hizo poner sobre la cruz. Estaba escrito: Jesús Nazareno, el rey de los judíos [...] $\mathrm{Y}$ estaba escrito en hebreo, en latín y en griego». En otra escena posterior (vv. 1726 y ss.) Febo-Cristo llega al jardín de Falerina (donde está el árbol mortal de la perdición) y muriendo ensangrentado en el árbol del pecado, lo convierte en el árbol de la vida del hombre, rescatado por el sacrificio de Cristo:

porque en términos se vea si en un árbol le venciste que él en otro árbol te venza muriendo yo porque él viva. (vv. 1778-1781) 
La pieza que mayor interés reviste en este sentido es la comedia La sibila del oriente, muchos de cuyos materiales se reutilizan en el auto sacramental, según práctica conocida en Calderón.

\section{La sibila del oriente y El árbol del mejor fruto}

Dos trabajos en particular se han ocupado de las relaciones entre la comedia y el auto. Menchacatorre ${ }^{27}$ considera que el auto es posterior a la comedia ${ }^{28}$, y lo califica de pieza más elaborada, con personajes mejor trazados y argumento de mayor unidad. La reina es «más compleja» en el auto, en su calidad de mujer angustiada en busca de la verdad movida por impulsos superiores a la protagonista de la comedia ( En la comedia no se ve esta lucha interior de Sabá» ${ }^{29}$ ), mientras que el personaje de Salomón resulta más engrandecido que en la comedia.

En conclusión afirma que

La sibila del oriente y El árbol del mejor fruto son obras que se parecen muchísimo. Hay parlamentos transcritos línea por línea y otros en que, aunque con palabras diferentes se repiten las ideas en el mismo orden en una y otra obra. Por otra parte, ambas comparten el tema común de la Exaltación de la Cruz, teniendo la segunda también el tema de la Eucaristía, como corresponde a los autos. No obstante se encuentran diferencias en cuanto a mejor presentación de los personajes y mayor unidad en el argumento del auto, lo que prueba que El árbol del mejor fruto es una obra posterior y más trabajada que La sibila del oriente. ${ }^{30}$

Más profundo es el análisis de Rull ${ }^{31}$, quien lo enmarca en un examen más general de las técnicas de transformación calderonianas desde la comedia al auto sacramental. Para Rull

27 Menchacatorre, 1983.

28 La opinión más segura, sin duda. Mussafia, 1869, p. 191-193 cree, sin argumentarlo, que la comedia "è un rifacimento di quest'auto», lo mismo que Meyer (ver Glaser, 1960, p. 382). Hartzenbusch, Comedias de Calderón, Madrid, Rivadeneira (BAE, 7), 1851, p. XVIII piensa también que la comedia es posterior al auto.

${ }^{29}$ Menchacatorre, 1983, p. 957.

${ }^{30}$ Menchacatorre, 1983, p. 961.

31 Rull, 2004, pp. 223-250. 
cualquier aproximación al género auto en relación con una comedia de igual tema tiene que partir forzosamente de la preexistencia, o preeminencia temporal si se quiere, de ésta ${ }^{32}$.

En lo que se refiere a La sibila del Oriente la integra en lo que llama "ciclo salomónico» de Calderón, caracterizándose en particular esta obra por su «historia esencialmente sagrada y llena de resonancias simbólico-proféticas», lo que le permite una adecuada reelaboración alegórica:

Para ello construyó su auto desde una perspectiva más descaradamente docente y, trascendiendo el episodio sacro, alegorizó el tema para dotarlo de una función esencialmente teológica. De esta manera nace el auto con un aire historial pero que progresivamente desemboca en una lección de didáctica alegórico-teológica, pues esa es su verdadera y nueva función ${ }^{33}$.

Señala igualmente Rull la diferencia en el tratamiento de la leyenda del árbol de la cruz en la comedia y el auto:

Mientras en la primera Sabá describe con minuciosidad (unos 150 versos) la historia del árbol adánico (la muerte de Adán y la visita de su hijo Set a su tumba, donde ha renacido el árbol, con lo que Dios mostraba el perdón a su padre), en el segundo, curiosamente, esta historia se abrevia notablemente (unos 25 versos), y lo que se detalla en perspectiva histórica es la lección teológica y de proyección redentorista de esta visión [...] el distinto tratamiento de ese material dramático refleja dos intenciones en apariencia semejantes pero en el fondo divergentes. En el primer caso se trata de exponer con detalle una leyenda para el mejor conocimiento narrativo de la historia, mientras que en el segundo, o se da ya por conocida esa historia, o no interesa en sí misma, sino como antecedente de su proyección religiosa actualizada y actualizante ${ }^{34}$.

A mi juicio la estructura del auto es algo más compleja de lo que apunta Rull: la leyenda del árbol adánico no tiene menor desarrollo en el auto, ya que no solamente aparece en un primer breve relato

32 Rull, 2004, p. 206.

33 Rull, 2004, pp. 208-209.

${ }^{34}$ Rull, 2004, pp. 249-250. 
(vv. 865 y ss.) sino que la retoma extensamente la reina de Sabá al final, justamente en las escenas de apoteosis de la cruz (vv. 1820 y ss.), y aún más, constituye el esqueleto estructural de todo el auto, sobre el cual se teje la serie de motivos alegóricos que irán fundiendo las referencias a la mujer y al tronco de los que vendrá la salvación, en antítesis a la otra mujer y al otro árbol de los que procedió el pecado original.

En cualquier caso comedia y auto comparten unos materiales comunes (los temas de Salomón y del árbol de la cruz) aunque sin duda las diferencias de ambas piezas son notables. Dejando a un lado los paralelos y reiteraciones de pasajes enteros, que se apuntan en las notas al texto, las principales modificaciones suponen sobre todo:

a) una reducción de elementos superfluos para la coherencia alegórica

b) un desarrollo de los motivos teológicos y refuerzo de los paralelismos antitéticos del primero y segundo Adán y de los dos árboles.

En las primeras escenas comedia y auto son muy semejantes: desaparece sobre todo el enfrentamiento entre Irán y Candaces, que implica cierto nivel anecdótico conflictivo en la acción dinámica de la comedia, pero que resulta inútil para el auto. La historia de Salomón observa pasajes casi iguales, con pequeñas variaciones. Conforme avanza la acción las diferencias se acentúan: Libio, el rey de Palmira, el gracioso Mandinga (con toda su carga cómica), los generales de David Joab y Semeí (que en la comedia simbolizan al buen y al mal ladrón crucificados con Cristo) desaparecen completamente del auto: constituyen amplificaciones de la acción innecesarias para la trama sacramental.

Tiene razón Menchacatorre al señalar la falta de búsqueda espiritual en la sibila de la comedia: en realidad Sabá, con cierta inverosimilitud, ya en su primera aparición de la comedia, profesa adoración al Dios uno y trino, y conoce el celestial madero ${ }^{35}$ que salvará al linaje humano; en otra ocasión (p. 1171) la misma reina expone, sin que se justifique su conocimiento, la doctrina trinitaria simbolizada en al árbol triforme:

${ }^{35}$ Ver La sibila del oriente, p. 1161. 


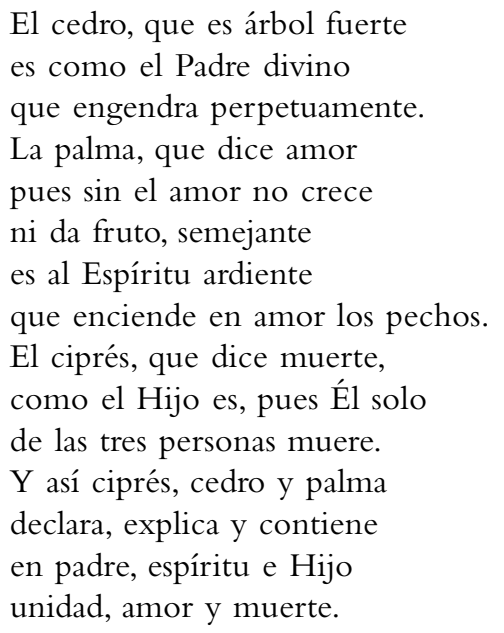

No hay, por tanto, ningún proceso gradual de investigación ni conversión, como el que articula en el auto el desarrollo del argumento. Nótese que la academia de ingenio en los jardines de Salomón se transforma en una academia filosófica que llega a discutir de la primera causa, para desembocar finalmente en una academia teológica, identificando esa causa de causas con Dios, cuyos atributos se van revelando en el discurso. La Idolatría desempeña en el auto una limitado, pero perceptible función de antagonista, que sirve para disponer mejor los razonamientos de Salomón, mientras que no tiene papel en la comedia. Toda esta parte de la pedagogía religiosa inserta en el esquema de academia de ingenio está mucho más desarrollada en el auto, respondiendo a la más densa intención doctrinal que apuntaba Enrique Rull.

La leyenda del árbol de la cruz y la expedición de Set se coloca en La sibila al final, como sucede con el segundo relato de la pieza sacramental, pero hay alguna dificultad añadida: el tercer acto de la comedia es demasiado corto (unos 650 versos), lo que hace suponer alguna pérdida de texto, haciendo dudosos los análisis sobre la composición y estructura de esta comedia. Según el relato de la comedia el árbol plantado después del diluvio parece ser la oliva traída en su pico por la paloma que envía Noé: debe de haber, pues, alguna falla textual con pérdida de un pasaje donde se contara el modo en que el árbol de la cruz llega al Líbano (y nada se dice de las tres semillas que explicarían la forma triple del árbol) y además se puede percibir una 
contaminación con versiones de la leyenda en las que el olivo era una de las maderas de la cruz, lo que se niega en los versos adyacentes que hablan solo del cedro, palma y ciprés... Creo, en suma, que esta comedia tiene problemas textuales que deberán ser estudiados. La leyenda recogida en La sibila del oriente se extiende en ella con cierta amplitud (pp. 1179-1180):

Llamó Adán a Set, su hijo, que de toda su familia era Set, joven hermoso, el hijo que más quería, y díjole así: [...]

llegarás a las murallas que con el cielo terminan, cuyas piedras son topacios, crisólitos y amatistas, y al ángel que está a la puerta, di que tu padre te envía por el óleo del Señor, que a él basta que se lo digas [...]. Llegó, en fin, al paraíso, [...]

Desde la puerta miró una visión exquisita en un árbol, cuyas hojas, secas, mustias y marchitas, desnudo el tronco dejaban que entre mil copas floridas de los árboles, él solo, sin pompa y sin bizarría, era cadáver del prado, y como todos vivían con almas, él solamente sin alma vegetativa, era un árbol esqueleto, con la armadura y sin vida. Éste el ángel le enseñó con el dedo, y dijo: «Mira el óleo de la piedad; aquél es, aunque está en cifra». 
Volvió a su padre con esto Set; y Adán, que conocía de la forma de aquel árbol la maravillosa enigma, le dijo así: «Set, yo muero; lo que mi amor determina es que me des sepultura en Hebrón, y mira encima de mi sepulcro que un árbol nace, que esto significa ver tú el árbol de la muerte cuando el árbol de la vida quieran piadosos los cielos, que nazca de mis cenizas». [...] Pasó el diluvio, y las aguas a su estancia recogidas dieron paso a la paloma que trajo la verde oliva del austro más riguroso que el diciembre determina. En el Líbano le puso, $\mathrm{y}$, como cosa divina, los siglos le veneraron, y los hombres le acreditan por palma, cedro y ciprés, porque no se determinan si es ciprés, si es palma o cedro, aunque todo parecía.

Llegó al Líbano Candaces, buscando maderas ricas para la casa de Dios, y cortarle determina. Trájole a Jerusalén, y la arquitectura misma por inútil le dejó entre estas selvas y ruinas, arrojado en un jardín, de donde, para que sirva de puente al Cedrón, le traen ocupación propia y digna de su virtud y piedad, 
y más al monte en que habita

la calavera de Adán,

pues Calvario se apellida.

Algunas glosas a "El árbol del mejor fruto»

La estructura del auto se articula en dos partes bastante equilibradas en su extensión. La primera se define por la dispersión y la preparación de dos proyectos básicos: el de Salomón, que quiere construir el templo de Jerusalén, y el de la reina de Sabá, que quiere indagar los secretos del bien y el mal, y después, al escuchar el relato de Irán, acudir a comprobar la sabiduría y riqueza del rey Salomón. La segunda reúne a los protagonistas en Jerusalén y anuda los hilos de la primera parte en la confluencia del sentido cristológico y eucarístico de los diversos elementos argumentales (historia de la reina de Sabá y de Salomón y leyenda del árbol de la cruz).

Cada una de estas partes se puede dividir en bloques y secuencias menores delimitadas por la métrica, los espacios dramáticos y escénicos y los motivos temáticos, y enlazadas por diversas isotopías y alusiones que se desarrollan progresivamente ${ }^{36}$.

La escena primera se sitúa en el primer carro, que representa la sala del trono, donde tiene lugar según el auto el sueño o visión profética del rey narrado en el libro 3 de los Reyes. Calderón diseña una escena dramática y musical con la visión de dos ninfas (ángeles, mensajeros de Jehová), con los rostros cubiertos, detalle este que alude a la imposibilidad humana de mirar a la divinidad cara a cara y que subraya la humildad de Salomón. Algunos elementos básicos se establecen en esta escena primera, como son los principales atributos de Dios a través de la invocación del rey y del significado de los nombres divinos:

Inmenso Jehová, de dioses
Dios sin principio ni fin,
de batallas Sabaot,
de ciencias Adonaí. (vv. 1-4)

36 Para un análisis más detallado remito al citado estudio preliminar de mi edición. 
Igualmente se establece la importancia de la fe como cimiento de la actuación de un rey perfecto y el encargo de la fábrica del templo, misión confiada a Salomón que supone el impulso para la acción argumental de la pieza.

Tras la visión baja el rey al tablado, y suenan chirimías que anuncian la llegada de Irán y Candaces, reyes tributarios a quienes Salomón encarga dos misiones conducentes a la construcción del templo.

Este bloque primero se dispone métricamente en romance -í, con algunos pasajes musicales y estribillos cantados, de distinta medida, englobados en el romance. La continuidad con la secuencia siguiente se marca en la misma forma métrica con igual rima: la visión, situada en un espacio onírico, da entrada a la acción «real» que va a iniciar su andadura en el nivel del tablado. La música de chirimías en forma de salva o saludo a los personajes que llegan subraya la transición a otro pasaje del mismo bloque temático.

El espacio dramático del segundo bloque es el mismo palacio de Salomón. Cada uno de los dos reyes subordinados recibe su encargo, parafraseando pasajes diversos de la Biblia, sobre todo 1 Crónicas, 22, 7-10. Salomón evoca el magnífico templo que debe acoger el arca de la alianza. Para construir este edificio y para su servicio ritual necesita materiales preciosos que han de traer sus flotas de dos lugares: del Líbano las maderas y de Sabá los perfumes:

\author{
De este pues sagrado Olimpo \\ habemos de conducir \\ leños a Jerusalén, \\ y tú, Candaces, has de ir \\ a talarles y a traer \\ de las palmas de Efraín, \\ de los cedros de Cadés \\ y cipreses de Setín \\ los troncos, porque en ciprés, \\ palma y cedro se ha de unir \\ tal trabazón que parezca \\ que nacen de una raíz. \\ Tú, Irán, has de ir al oriente, \\ y de mi parte decir \\ a Nicaula de Sabá, \\ que es su docta emperatriz, \\ que si mi amistad desea
}


para servirse de mí

me ferie de los sabeos

aromas de su país. (vv. 259-278)

El parlamento de Salomón hace referencia a las palmas de Efraín, cedros de Cadés y cipreses de Setín, aludiendo a la simbología divina de estos lugares y también a la leyenda del árbol triforme (palma, cedro y ciprés) de la cruz que se desarrolla en el resto del auto.

Este segundo bloque termina recopilando Salomón los dos motivos de los árboles y la reina de Sabá (un madero y una mujer) que siente proféticamente como un misterio feliz que se desvelará en un futuro, pero que aún permanece entre nieblas. En su momento se podrá identificar la verdadera dimensión de esta mujer (la reina de Sabá) como tipo o figura de la Virgen, y la del madero como figura de la cruz, es decir, anuncio de la salvación de la humanidad por Cristo, descendiente en efecto de la casa de David:

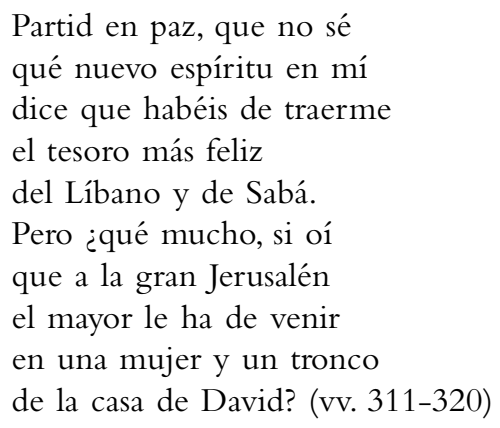

Los enviados parten a sus misiones y los espacios dramáticos cambian a Sabá y al Líbano, aunque su presentación escénica juega con diversas categorías permitidas por el mecanismo alegórico: el espacio tomado como referencia «real» es la corte de Sabá, mientras que la actividad de Candaces en el Líbano puede observarla el espectador a través de una visión de Idolatría (la cual se halla en Sabá), que abre un tipo de escenario onírico, no sujeto a la tiranía del tiempo ni del espacio, según la libertad alegórica ${ }^{37}$.

37 Ver Arellano, 2001, pp. 185-189. 
Este segundo bloque de la primera parte, al que me estoy refiriendo, puede considerarse formado por tres subsecuencias marcadas por cambios métricos y de espacio.

a) En un segundo carro, con toda probabilidad, se sitúa la acción en el reino de Sabá, cuya reina es una vidente profetisa, obsesionada por la investigación del bien y del mal:

\author{
La sibila soberana \\ de la gran India Oriental, \\ emperatriz de Etiopia, \\ reina invicta de Sabá, \\ inspirada del fervor \\ que la asiste celestial \\ retirada está a inquirir \\ secretos del bien y el mal. (vv. 321-328)
}

La aparición de la reina en trance profético es de gran impacto visual, con el cabello y las ropas descompuestos (vv. 417-418) y dialoga intertextualmente con el pasaje de la Eneida (libro III) referido a la sibila de Cumas, que tiene el mismo modo de profetizar, arrojando al viento hojas de árboles con versos escritos que se ordenan luego al azar para ofrecer las predicciones. La versión calderoniana integra, naturalmente, motivos básicos de la doctrina católica que dirigen la percepción del espectador para que interprete correctamente al personaje de la sibila: el espíritu que invoca la reina es "divino", usa la terminología escolástica de "causa de causas» para Dios, se refiere a la salud de los mortales (la redención), etc. Este es un Dios ignorado por la Idolatría, la cual irónicamente se empeña en averiguar de qué Dios se trata, y sugiere el modo de leer el misterioso vaticinio: las hojas dispersas no permiten la comprensión de un mensaje ininteligible, pero si se leen juntas, el mensaje constituye una octava real de lectura literal comprensible, pero de sentido profundo todavía oscuro: el resto del auto iluminará ese sentido que alude a un madero celestial antídoto de otro árbol primero de veneno mortal:

«Un celestial, un singular madero...

$\mathrm{I}^{\circ}$

... con dulce fruta en su sazón cogida...

$2^{\circ}$

... antídoto ha de ser de aquel primero... 


$\begin{array}{ll}\mathrm{I}^{\mathrm{a}} & \ldots \text { porque uno muerte dé y otro dé vida,... } \\ 2^{\mathrm{a}} & \ldots \text { y cuando el parasismo vea postrero... } \\ \mathrm{I}^{\mathrm{a}} & \ldots \text { la fábrica del orbe desunida... } \\ \text { ASTREA } & \ldots \text { los dichosos serán los señalados... } \\ \text { IDOLATRÍA } & \ldots \text { cuando con él a juicio sean llamados». }\end{array}$

(vv. 459-466)

La Idolatría, desorientada e inquieta, se propone estorbar las investigaciones de la reina, para evitar que llegue a descubrir al verdadero Dios de Israel. Sus reflexiones son interrumpidas por la llegada de la nave de Irán. En algún momento han bajado al tablado, donde llega el enviado de Salomón.

b) Una nueva subsecuencia (segunda de este bloque, en romance -é-a) presenta la llegada de Irán al reino de Sabá en cumplimiento de su misión. El diálogo de la reina y de Irán abunda en imágenes exóticas y brillantes que evocan la riqueza y maravillas de la isla de Merol, luego llamado reino de Sabá, siguiendo tradiciones diversas recogidas entre otros por Pineda en De rebus Salomonis. La evocación del auto repite con algunas variaciones la de la comedia La sibila del oriente (p. 1164), excitando la admiración del oyente por los ámbitos exóticos ${ }^{38}$, admiración que va en aumento al contraponer Irán en su parlamento a las majestades y riquezas de Sabá las aún mayores de Salomón, en una nueva paráfrasis de la Sagrada Escritura (3 Reyes, 4, 21-31).

Lo que más impresiona a la reina, con todo, es la ciencia de Salomón, capaz de resolver todas las dudas. Intrigada, la sibila decide viajar a Jerusalén ignorando las dificultades que interesadamente le opone la Idolatría.

De la sabiduría del rey espera Sabá la solución a una duda que le obsesiona, y que no es otra que el conocimiento del verdadero Dios o causa primera, principio sin principio y fin sin fin:

podrá ser me dé algún rasgo,

algún viso, alguna seña,

alguna sombra o figura

de aquella causa primera,

38 Arellano, 2006. 
que principio sin principio

el ser fin sin fin es fuerza. (vv. 779-784)

Despechada, la Idolatría invoca a Baal para que en competencia del Dios de Israel la ayude a impedir el progreso de la reina en su indagación y a destruir el árbol al cual el vaticinio calificaba de antídoto, pero la acomete un extraordinario desmayo con una misteriosa visión en la que puede observar a Candaces y sus tropas talar los árboles del Líbano, entre los cuales destaca uno maravilloso, precisamente el antídoto temido por la Idolatría.

c) El espacio dramático onírico debe de situarse en un tercer carro, y acoge la actividad de Candaces en el Líbano, segunda de las misiones encargadas por Salomón, en romance -é-e. Para subrayar la relación de las dos, Calderón dispone dos espacios distintos pero no completamente separados, ya que el segundo (Líbano) se introduce a través de la visión de un personaje (Idolatría) situado en el primer espacio dramático (Sabá). Al final de la subsecuencia Idolatría confirma que el pasaje del Líbano responde a esta técnica de la visión, que vuelve a reunir el árbol y la mujer, ambos encaminados hacia Jerusalén, centro en el que los distintos elementos del auto van a confluir en la segunda parte para que se revelen los sentidos místicos de los sucesos, personajes y objetos que se diseminan en la primera:

IDOLATría Dioses, valedme,

que he visto infinitos siglos

en solo un instante breve,

pues en solo un breve instante

he visto tan diferentes

cosas como hoy en Sabá

y en el Líbano suceden.

Dígalo allí el misterioso

árbol de las tres especies,

dígalo aquí la jornada

que a Jerusalén previene

Sabá puesta ya en camino

y dígalo finalmente

el ir a Jerusalén

entrambos, donde parece

que $\sin$ verse el uno al otro

se han citado para verse. (vv. 974 y ss.) 
El misterioso árbol de las tres especies es el núcleo argumental del auto: en el escenario del Líbano, Candaces se dispone a cortar los árboles necesarios. Los hebreos buscan un árbol admirable, que según sus tradiciones llevó a ese monte un nieto de Noé llamado Jericó. Al cortar uno de los troncos la copa vierte sangre, y Candaces rehusa toda responsabilidad en la tala, que los hebreos insisten en hacer ${ }^{39}$. Al caer el árbol se producen eclipses y terremotos, y advierten asombrados que está formado de tres especies, palma, cedro y ciprés.

Candaces, como la Idolatría, no comprende bien todos estos sucesos y «jeroglíficos», que irán desvelándose conforme avanza la acción ${ }^{40}$ :

Todos

CANDACES
¿Qué enigma es este?

No sé, que aunque dice mucho

es poco lo que se entiende

de un jeroglífico que

en una raíz contiene

tres cosas en sí distintas

que son una solamente,

significando en las tres

si a sus símbolos se atiende

en cedro, palma y ciprés

duración, victoria y muerte.

Llevadle a Jerusalén

vosotros, porque yo al verle

tan prodigioso no quiero

tener parte en él. (vv. 954-970)

La segunda parte del auto reúne todos los elementos diseminados en la primera. De la corte de Sabá y del monte Líbano la acción se traslada a Jerusalén, donde convergen la reina y el árbol. Esta segunda parte (compuesta por un tercer bloque escénico principal) puede dividirse en cuatro secuencias (la primera en redondillas, la segunda

${ }^{39}$ No hace falta anotar que es evocación de la actitud de Pilatos en la Pasión de Cristo, que hace recaer toda la responsabilidad en el pueblo judío.

${ }^{40}$ En la versión, muy parecida en este pasaje, de La sibila del oriente (p. 1171) se ofrece en este mismo instante la explicación trinitaria del árbol, que no es pertinente en el auto. 
en silva de consonantes, la tercera en romance en -é con algunas otras formas métricas englobadas y pasajes musicales de medidas diversas, y la cuarta en romance -é-o como forma dominante, con algunas otras englobadas o adherentes, a menudo en pasajes musicales hexasilábicos).

a) El pasaje en redondillas tiene por núcleo el famoso juicio de Salomón (3 Reyes, 3, 16-28) de las dos madres y el hijo muerto. Es un motivo que sirve de breve apertura al tema de la sabiduría del rey: no se dramatiza, sino que se narra en boca del mismo Salomón, quien se apresura a declarar que toda sabiduría y todo bien procede de Dios. La conversación del rey con Eliud se interrumpe con el regreso de Irán que procede a narrar su viaje.

b) Irán trae noticias de la reina de Sabá, que está a punto de llegar a Jerusalén, atraída por la grandeza de Salomón, y Candaces, que también regresa en ese momento, da noticia del árbol extraordinario que ha talado para el templo, "porque es leño con alma / de un cedro, de un ciprés y de una palma» (vv. 1093-1094).

La disposición paralela e inmediata de los parlamentos de ambos subraya la progresiva confluencia de los dos hilos argumentales, como resalta el propio Salomón:

Los dos me habéis logrado las dos cosas que más he deseado, que no sé lo que infiero en mí de una mujer y de un madero que han de ilustrar con majestad no escasa de Dios el templo y de David la casa; (vv. 1095-1100)

c) La tercera secuencia se concentra en la entrada triunfal de la reina en Jerusalén. La música recibe a Sabá con una paráfrasis del Cantar de los cantares, en romance en -é («Morena soy, pero hermosa, / hijas de Jerusalén»). Salomón invita a la reina a descansar en el alcázar de Sión mientras se prepara la entrada solemne en Jerusalén, y los personajes hablan y caminan en tanto suena la música y repiten las coplas para dar tiempo a las diversas evoluciones de todos ellos. Ahora se anuncia el episodio del madero convertido en puente al usarse el tronco del Líbano como refuerzo para asegurar el paso de la reina por el arroyo Cedrón. 
En el ínterin la reina se dispone a plantearle a Salomón una serie de enigmas. La secuencia se cierra con la preocupada glosa de la Idolatría (vv. 1283 y ss.) que vuelve a poner de relieve el misterio para ella peligroso que suponen en Jerusalén esa mujer y ese madero, desarrollando la paridad contrastiva de los dos paraísos y los dos árboles:

IDOLATRÍA

Cruel

genio de la Idolatría, ya estás en Jerusalén, que a oposición del primero segundo paraíso es. Corramos la paridad.

¿Qué es lo que contuvo aquel?

Un árbol del bien y el mal. ¿Y este? Del mal y del bien otro árbol, pues dice vida el cedro y muerte el ciprés. [...]

¿Qué más hubo allí? Hubo una mujer que se creyó infiel de las astucias del áspid; aquí infiel hay otra, pues idólatra ella y yo somos el áspid y la mujer. Si allí el árbol del peor fruto para entrambos fue aquel árbol, ¿por qué este sea tengo de temer el árbol del mejor fruto?

d) La cuarta secuencia es la culminación del argumento y la revelación más clara del asunto ${ }^{41}$. Un pasaje descriptivo en redondillas construye el espacio dramático para el certamen de ingenio: el jardín de Salomón, espacio cultivado para el juego cortesano, locus amoenus de flores y perfumes. Los enigmas y preguntas que la reina propone a la sabiduría de Salomón están ya en romance, con las inserciones apuntadas en momentos musicales.

41 Para esta distinción ver Arellano, 2001, p. 109. 
La primera pregunta es si el poder humano podrá crear una flor, dificultad que se ilustra con la prueba práctica de distinguir unas flores artificiales muy bien fabricadas de otras naturales. Salomón niega al hombre el poder creador, que pertenece únicamente a Dios.

Astrea pregunta entonces si de una causa pueden proceder dos efectos, como parece mostrar el ejemplo del cristal, que en forma de lente a unos disminuye el tamaño de la letra y a otros se lo aumenta. Salomón responde primero al problema aplazado de distinguir las flores naturales y las artificiales: las naturales son aquellas frecuentadas por las abejas y las artificiales las rodeadas de moscas. Pero de esta circunstancia Salomón extrae curiosamente una lección de humildad que ilustra la respuesta principal de la incapacidad del hombre para emular al Creador:

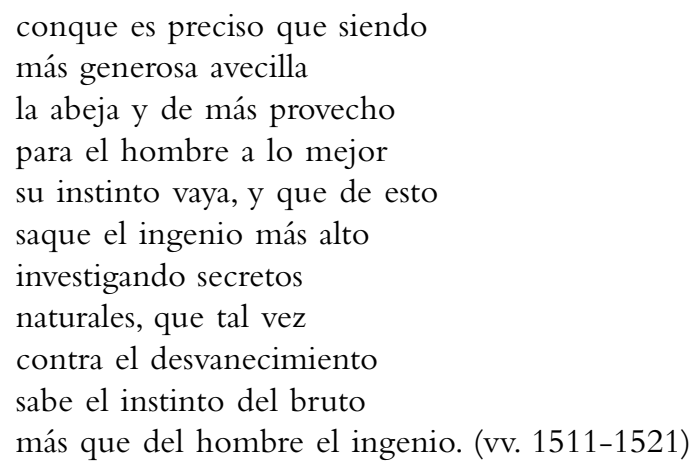

Sobre el asunto del cristal expone Salomón un argumento relativo a los efectos y las causas según doctrinas de las ciencias naturales y la filosofia de la época, pero lo que realmente le interesa es suscitar la cuestión de la causa de causas o causa primera, que introduce algo arbitrariamente (siguiendo más bien una técnica de asociación de ideas) en la conversación:

el que se puedan seguir de una causa dos efectos, y si a otra causa de causas pasara, que vieras creo, Astrea, que efecto no hay en cuantos el universo 
contrarios tiene que de ella no dependa. (vv. 1564-1572)

Este concepto escolástico que remite a la segunda de las cinco pruebas de la existencia de Dios que explica Santo Tomás, asombra a la Idolatría, quien identifica la primera causa con los dioses paganos, de poder y atribuciones divididos, que se hallaron el mundo creado por el acaso. Salomón obliga a la Idolatría a "proceder en infinito", de lo que ella protesta, dando pie al rey para declarar la doctrina del Dios único, infinitamente bueno, sabio y poderoso, el Dios de Israel, en suma (vv. 1635 y ss.).

Del torneo de ingenio se ha desembocado en un debate teológico sobre la definición del verdadero Dios, y el anuncio mesiánico de un hombre y Dios que enmendará el yerro de los primeros padres. La doctrina de la hipóstasis se ejemplifica acudiendo al motivo de las flores que ha sido objeto de la previa discusión ingeniosa y filosófica: se puede hacer un ramillete que mezcle flores naturales y artificiales; del mismo modo el hombre mezcla cuerpo y alma. Si a ese hombre compuesto de elementos materiales y espirituales se une Dios, admitiendo la persona divina del salvador la naturaleza humana, se produce la unión hipostática en Cristo, que tiene dos naturalezas en la unidad de la persona divina. Al indicar Astrea la repugnancia que halla entre lo celeste y lo terreno, que parece obstaculizar esa unión, Salomón vuelve al ejemplo del cristal para exponer el dogma de la virginidad de María, madre del redentor: el poder de Dios puede hacer que la cualidad terrena de una mujer quede superada, de modo que de ella nazca el Mesías, sin que «de su cristalino espejo / padezca la integridad / ni lesión ni detrimento» (vv. 1716-1719).

Para sugerir el rigor lógico que aparentemente ordena los discursos de Salomón abunda el léxico de este campo en el pasaje que comento (1367 y ss.:): concedo, aunque, pues, supuesto, argumento, por razón de, no es contrario, a contrario, bien pruebo, causa de causas, mi argumento, convencerte puedo, ya que el argumento pones, proceder en infinito, etc.

Sembradas las preocupaciones teológicas en el certamen del jardín, llega el momento de pasar por el puente del Cedrón para continuar con las fiestas de la entrada real. En ese momento la sibila experimenta una visión y descubre la verdadera calidad del tronco que han usado para el puente, narrando la historia legendaria del árbol del mejor fruto (vv. 1820 y ss.): 


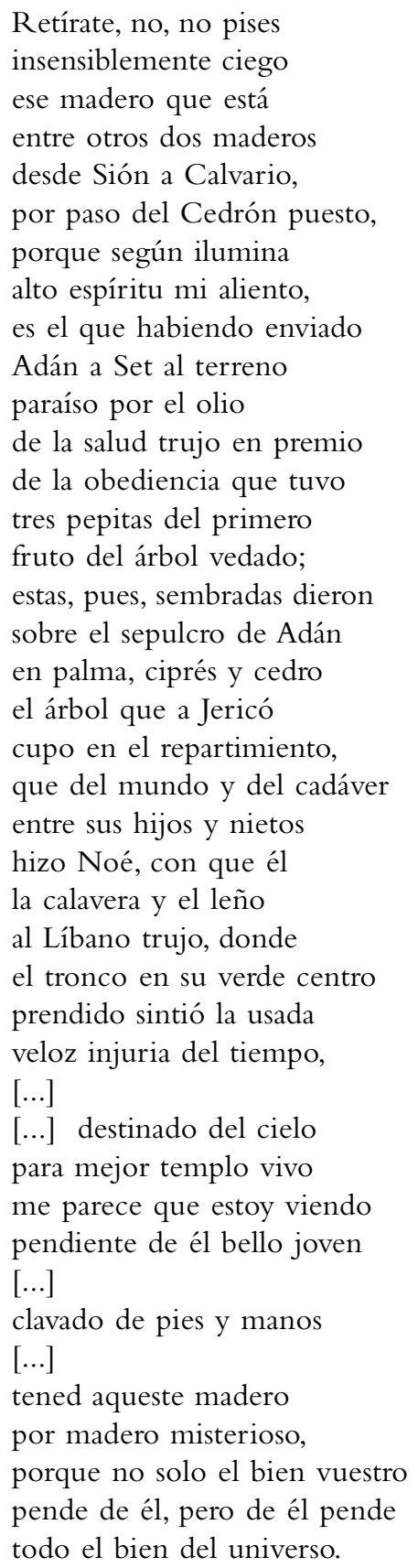


El efecto del árbol decide la conversión definitiva de la reina, que arroja a la Idolatría de su lado y abraza la ley de Israel en la espera del misterioso salvador.

Una nueva visión da fin al auto, cuando se abre un carro que deja ver una cruz cuyo sentido explica la misma sibila, identificando el árbol del mejor fruto con este leño fuente de gracia, manantial de los sacramentos, entre los cuales destaca el de la Eucaristía:

Este es el ligno en quien pende

la salud del mundo entero,

pues de la sangre que de él

inundará al universo

divina fuente de gracia

a los siglos venideros

correrá por siete caños

que son siete sacramentos

la eterna salud del hombre, siendo el principal entre ellos

aquel divino milagro,

aquel sagrado portento,

de que estén transubstanciados

en pan y vino alma y cuerpo,

recobrándole en su gracia,

por ser de la gracia augmento. (vv. 1942-1957)

Como epílogo Sabá y la música repiten la octava real que concentraba en el primer oráculo de la sibila la cualidad redentora de ese árbol «antídoto» del primero, con su dulce fruta cogida en sazón: Cristo, en suma, y el sacramento de la Eucaristía. 


\section{Bibliografía}

Apócrifos del Antiguo Testamento, ed. A. Díez Macho, Madrid, Cristiandad, 1983, tomo II.

Arellano, I., Estructuras dramáticas y alegóricas en los autos de Calderón, Pamplona / Kassel, Universidad de Navarra / Edition Reichenberger, 2001.

- «Aspectos de los exótico en el teatro de Calderón», en Le arti della scena e l'esotismo in etá moderna, ed. F. Cotticelli y P. Maione, Napoli, Turchini, 2006, pp. 175-190.

Calderón de la Barca, P., Comedias, ed. J. E. Hartzenbusch, Madrid, Rivadeneira (BAE, 7), 1851.

- El jardín de Falerina, ed. L. Galván y C. Mata, Pamplona / Kassel, Universidad de Navarra / Edition Reichenberger, 2007.

- La humildad coronada, ed. I. Arellano, Pamplona / Kassel, Universidad de Navarra / Edition Reichenberger, 2002.

- La inmunidad del sagrado, ed. J. M. Ruano de la Haza, D. Gavela y R. Martín, Pamplona / Kassel, Universidad de Navarra / Edition Reichenberger, 1997.

- La lepra de Constantino, ed. L. Galván y R. Arana, Pamplona / Kassel, Universidad de Navarra / Edition Reichenberger, en prensa.

- La redención de cautivos, en Obras completas, III, Autos, ed. Á. Valbuena Prat, Madrid, Aguilar, 1987.

- La sibila del oriente, en Obras completas. Dramas, ed. Á. Valbuena Briones, Madrid, Aguilar, 1987.

- Obras completas, III, Autos, ed. Á. Valbuena Prat, Madrid, Aguilar, 1987.

- Primer refugio del hombre y probática piscina, ed. R. Zafra, Pamplona / Kassel, Universidad de Navarra / Edition Reichenberger, en prensa.

- Primero y segundo Isaac, ed. Á. Cilveti y R. Arias, Pamplona / Kassel, Universidad de Navarra / Edition Reichenberger, 1997.

Combes, L. de, «La légende du bois de la Croix», L'Universitè Catholique, 36, 1901, pp. 425-435.

DANiÉlou, J., Les symboles chrétiens primitifs, Paris, Éditions du Seuil, 1961.

Glaser, E., "Calderón de la Barca's La sibila del oriente y gran reina de Saba», Romanische Forschungen, 72, 1960, pp. 381-403.

Gretser, J., De Cruce Christi, Ingolstadt, ex typographia Adami Sartorii, 1600.

- De Santa Cruce, Ingolstad, ex typographeo Ederiano, apud Elisabetham Angermariam..., 1616.

Hartzenbusch, J. E., ed., Calderón de la Barca, P., Comedias, ed. J. E. Hartzenbusch, Madrid, Rivadeneira (BAE, 7), 1851.

Josefo, F., Antigüedades judías, ed. J. Vara Maldonado, Madrid, Akal, 1997. 
La cueva de los tesoros, introducción y traducción de P. González Casado, Madrid, Ciudad Nueva, 2004.

Lapide, C. a, Commentarii... R. P. Cornelii a Lapide, Paris, Ludovicum Vives, 1878.

Lipsius, J., De Cruce libri tres, Antuerpiae, ex Officina Plantiniana, 1599.

Menchacatorre, F., «Relaciones entre La sibila del Oriente y El árbol del mejor fruto", en Calderón. Actas del Congreso Internacional sobre Calderón y el Teatro Español del Siglo de Oro, ed. L. García Lorenzo, Madrid, CSIC, 1983, 3 vols., t. II, pp. 955-961.

Mussafia, A., «Sulla leggenda del legno della Croce», Sitzungsberichte der philosophisch-historischen Classe der kaiserlichen Akademie der Wissenschaften, 63, 1869, pp. 165-216.

PIneda, J., Salomon praevius id est de rebus Salomonis, Lugduni, apud Horatium Cardon, 1609.

Rull, E., Arte y sentido en el universo sacramental de Calderón, Pamplona / Kassel, Universidad de Navarra / Edition Reichenberger, 2004.

Solórzano Pereira, J. de, De indiarum iure, liber I, ed. C. Baciero et al., Madrid, CSIC, 2001.

Tirso De Molina, Obras dramáticas completas, III, ed. B. de los Ríos, Madrid, Aguilar, 1958.

Valdivielso, J., Teatro completo, ed. R. Arias y R.V. Piluso, Madrid, Isla, 1981.

VorÁgine, S. de la, La leyenda dorada, ed. Fr. J. Macías, Madrid, Alianza, 1982, 2 vols. 
